\title{
Wheat-market Flows in the Punjab
}

\section{PETER A. CORNELISSE*}

The first of two articles on the operation of the wheat market in Pakistan, the present article describes the magnitude and composition of wheat flows between farmers, middlemen and consumers in the Punjab. The flows emanating from the agricultural sector and those moving from various sources of supply to consumers have been separately illustrated in two diagrams. A wheattrade table shows the volumes of wheat handled by traders and the position which groups of traders assume in the wheat-trade chain. Further, a brief account is given of the activities of these groups of traders.

\section{INTRODUCTION}

Wheat is by far the most important crop in Pakistan. A few figures can illustrate this statement. For example, the value added by wheat production alone represents approximately 7 percent of the national income. Further, the land used for wheat occupies just over 35 percent of the total cropped area in Pakistan, whereas cotton and rice, which are the next most important agricultural crops of the country, each use about 10 percent of the cropped area [7]. And in 1979, expenditures on wheat and flour constituted, on average, 9.4 percent of household budgets and 18.4 percent of food expenditures. The corresponding figures for rice, the second largest food-expenditure item, were 2.1 percent and 4.2 percent, respectively [8]

A large part of the wheat harvest, about 40 percent, is used by farmers for own consumption and another part, about 10 percent, is paid to agricultural workers as wages in kind. The remaining part is mostly sold and eventually reaches other consumers after a series of transactions in various trade channels. Obviously, for this latter group of consumers the proper functioning of the wheat-trade chain is a matter of considerable importance. But the same conclusion applies to farmers on the other side of the trade chain, who supply this wheat. In order to be able to judge

*The author is Professor of Development Planning, Erasmus University, Rotterdam. This article is based on a part of a study jointly carried out by staff members of the Centre for Development Planning, Erasmus University, Rotterdam and the Pakistan Institute of Development Economics, Islamabad, with financial support from the Dutch Ministry for Development Co-operation. 
the performances of the wheat market in terms of socio-economic efficiency, ${ }^{1}$ however, information is needed on several aspects, such as on the groups of traders that can be distinguished and the functions each of them performs $\boldsymbol{v}$ is- $\boldsymbol{a}$-vis farmers and producers and on the conditions of the transactions. Such information is not readily available notwithstanding the considerable relevance of the matter for policy reasons as illustrated by the above-mentioned figures. In fact, in this case the information needed has been obtained by means of a survey carried out among farmers, wheat traders, millers and consumers in the Punjab, Sind and the NWFP in June 1982. ${ }^{2}$

This article is primarily concerned with the network of wheat flows between farmers, traders and consumers in order to bring out the composition and the relative importance of individual flows discussed subsequently. In this description it will also be possible to deal with the functions performed by wheat traders and the relative strength of traders in transactions with other market actors. In a subsequent article, which will also examine in more detail the consumption of wheat in Pakistan, a more comprehensive evaluation will be given of the Pakistani wheat market.

The figures presented here all refer to the Punjab which is the most important province in matters relating to production, consumption and trade of wheat. The main reason for excluding the other provinces is that the wheat-trade table, which plays a central role in this presentation, appears to be sufficiently robust only for the Punjab. The basic data required for the construction of such a table and collected through the above-mentioned survey are equally reliable for the other provinces, but the trade patterns of individual actors in the groups distinguished in the table show great variation and this precludes application of the calculation procedure designed for this purpose. For reasons of consistency, the flows of wheat according to uses by farmers and the flows leading to consumers refer also to the Punjab only. Readers interested in the corresponding figures for Sind and the NWFP are referred to the final report of this research project [2].

\section{FARMERS' USES OF WHEAT ${ }^{3}$}

The flows of wheat in and from the farm sector in the Punjab in 1982 are presented in Diagram 1. The figures indicate the relative size of the flows in percentages of the harvest volume, while disregarding losses. The width of flows in the diagram corresponds with their relative size. For example, rent payments in the

${ }^{1}$ In order to obtain an operational interpretation of this concept, it is considered here to be composed of the following interrelated items: cost efficiency, degree to which interests of farmers and consumers are served, and fair distribution of negotiating power among market actors.

${ }^{2}$ The survey included 1045 farmers, 177 middlemen, 29 village shops, 86 ration shops, 177 millers and 1451 consumers.

${ }^{3}$ This section is largely based on van Gaalen [3] and Roks [9].
Punjab - still mostly settled in kind - constitute approximately 10 percent of the wheat harvest. (In Sind, where the incidence of tenancy in agriculture is much higher, rent payments approach even a level of 40 percent of the harvest.) The flow of rent payments has been indicated by a loop, because payments by tenants are receipts of land owners and, therefore, do not leave the farm sector. This also applies to the flow of wheat used as seed and fodder, but as this flow reduces the volume available for consumption and sale, it leaves the system. It can be added in passing that the seed component encompasses approximately 4 percent of the harvest, indicating that farmers still depend to a very large degree on wheat seed retained from their previous harvest, a situation which seriously endangers future wheat supplies.

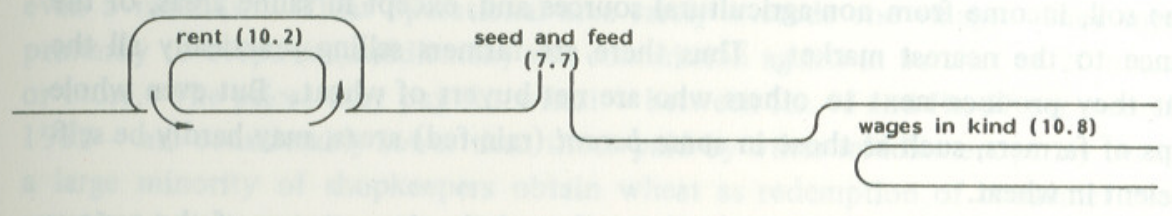

own consumpt (38.7)

harves

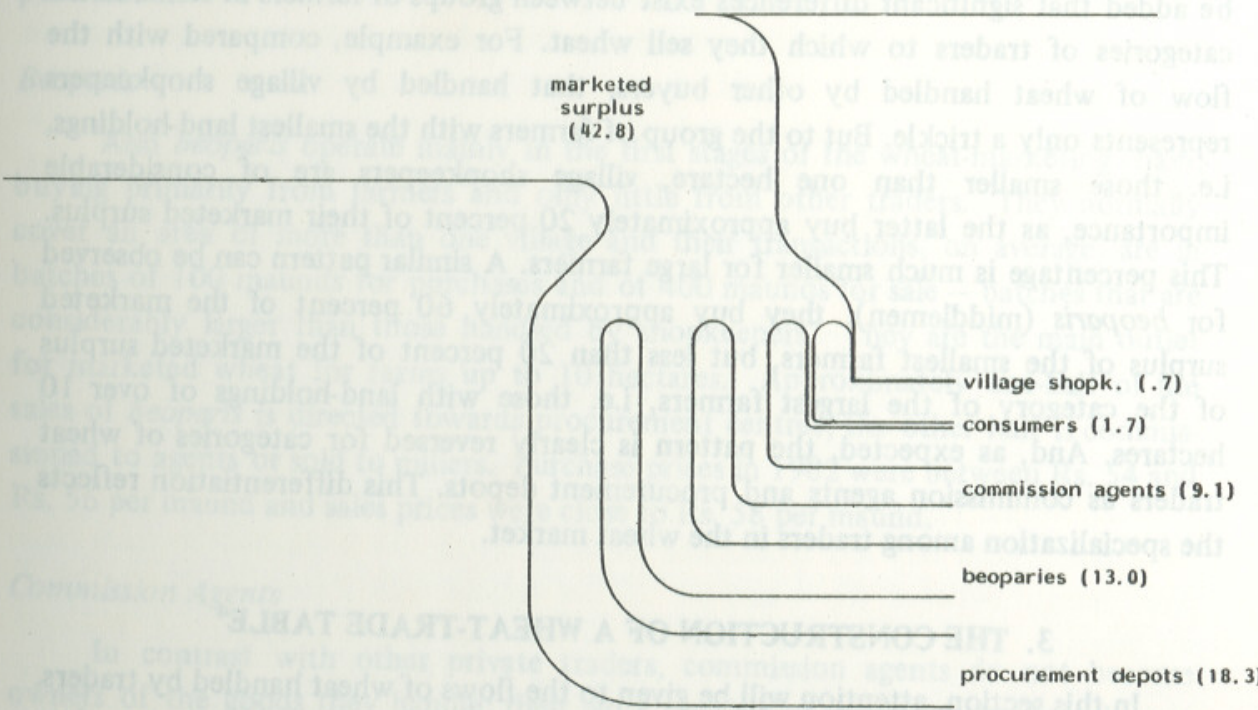

Flow Diagram 1: Uses of Wheat by Farmers : Punjab, 1982 
The largest flow in the diagram, the one relating to "own consumption", travels the shortest distance. Note that even in the Punjab, a relatively commercialised province, it includes nearly 40 percent of the harvest. Also, payments of wages in kind to permanent, seasonal and other workers still absorb a considerable portion of the wheat harvest.

Even in this brief presentation, the marketed surplus deserves some closer attention. As indicated in the diagram, this part of supply constitutes just over 40 percent of the wheat harvest for the Punjab agricultural sector as a whole. But the aggregate figure conceals a wide variation in the degree of market orientation among individual farmers. A more detailed analysis shows that the percentage of wheat sales to wheat harvest of individual farmers is a function of not only such obvious factors as the area of land used for wheat, and tenurial status, but also of the quality of the soil, income from non-agricultural sources and, except in saline areas, of the distance to the nearest market. Thus there are farmers selling practically all the wheat they produce next to others who are net buyers of wheat. But even whole groups of farmers, such as those in some barani (rain-fed) areas, may hardly be selfsufficient in wheat.

The figures in the diagram specifying the relative importance of the various market outlets for farmers in the Punjab speak for themselves. But here it must also be added that significant differences exist between groups of farmers in terms of the categories of traders to which they sell wheat. For example, compared with the flow of wheat handled by other buyers, that handled by village shopkeepers represents only a trickle. But to the group of farmers with the smallest land-holdings, i.e. those smaller than one hectare, village shopkeepers are of considerable importance, as the latter buy approximately 20 percent of their marketed surplus. This percentage is much smaller for large farmers. A similar pattern can be observed for beoparis (middlemen): they buy approximately 60 percent of the marketed surplus of the smallest farmers, but less than 20 percent of the marketed surplus of the category of the largest farmers, i.e. those with land-holdings of over 10 hectares. And, as expected, the pattern is clearly reversed for categories of wheat traders as commission agents and procurement depots. This differentiation reflects the specialization among traders in the wheat market.

\section{THE CONSTRUCTION OF A WHEAT-TRADE TABLE}

In this section, attention will be given to the flows of wheat handled by traders. A considerable portion of these flows consists of mutual trade of wheat traders which cannot be described clearly in a flow diagram. In order to meet this problem, a table has been constructed - resembling in design the familiar input-output table

${ }^{4}$ This section is largely based on [1]. which also presents in absolute terms the flows between wheat traders and their suppliers and between traders and subsequent users of wheat. Before we discuss the construction of this wheat-trade table, we give below a brief account of the main activities of the private wheat-traders included in the table.

\section{Characteristics of Private Wheat-Traders in the Punjab ${ }^{5}$}

\section{Village Shopkeepers}

For village shopkeepers, wheat trade is only a sideline activity and the volumes they handle are very small: between 25 and 150 maunds [1] per shopkeeper. They buy exclusively from farmers and, typically, in batches which often are of less than even 5 maunds. ${ }^{6}$ Their operational area rarely exceeds one village. They supply primarily to beoparis (middlemen) and commission agents in batches of 20 maunds or more. The prices they pay for wheat - between Rs. 45 and Rs. 52 per maund in 1982 - are considerably lower than those paid by other middlemen, partly because a large minority of shopkeepers obtain wheat as redemption of consumer credit provided by them during the off-season and also because the small batch size raises the handling costs per unit. Sales prices in 1982 ranged between Rs. 50 and Rs. 56 per maund.

\section{Beoparis}

Also beoparis operate mainly in the first stages of the wheat-marketing chain, buying primarily from farmers and only little from other traders. They normally cover an area of more than one village and their transactions, on average, are in batches of 100 maunds for purchases and of 400 maunds for sale - batches that are considerably larger than those handled by shopkeepers. They are the main outlet for marketed wheat for farms up to 10 hectares. Approximately one-half of the sales of beoparis is directed towards procurement centres; the other half is commissioned to agents or sold to millers. Purchase prices in 1982 were between Rs. 54 and Rs. 56 per maund and sales prices were close to Rs. 58 per maund.

\section{Commission Agents}

In contrast with other private traders, commission agents do not become owners of the goods they handle; their work consists of mediating between buyers and sellers. According to our survey, most agents are engaged by sellers to find

\footnotetext{
${ }^{5}$ For a very useful survey of operations of procurement centres in the Punjab, see [5].
} 
buyers, ${ }^{7}$ but there is a marked difference between the pattern of trade of agents handling less and that of agents handling more than 25,000 maunds of wheat per year. Still, in general it appears that the largest part of the incoming flow of wheat originates from farmers, especially large farmers, whereas a considerable portion of the outgoing stream reaches procurement centres. In agreement with general expectations, most commission agents operate on the mandi level, ${ }^{8}$ but the considerable number of them operating in villages must not be overlooked. Further, it is worth while noting that commission agents regularly provide credit to their customers, a practice that is much less common among other traders. Transaction prices in 1982 were mostly between Rs. 56 and Rs. 57.50 per maund and handling costs and commission charged varied between Rs. 0.50 and Rs. 2.00 per maund,

\section{Wholesalers}

Wholesalers are also active mainly on the level of mandis and, like commission agents, handle relatively large volumes of wheat. They appear to hold stocks more often than other private traders, possibly because they sell a considerable portion of their turnover in wheat to millers who have an interest in a regular supply over time. Since their position is at the end of the wheat-market chain, they also appear to be engaged in reduction of batch sizes. In 1982, their purchase prices varied only little between Rs. 56 and Rs. 57 per maund with sale prices during the peak season between Rs. 58 and Rs. 62 .

\section{General Remarks}

Procurement depots - which absorb approximately three quarters of the marketed volume - dominate the wheat market in the Punjab. In connection with this, the procurement price (Rs. 58 per maund in 1982) strongly influences the price in wheat transactions among private actors. Normally, this price is determined by deducting handling charges from the procurement price, where charges appear to vary positively with the distance to the nearest depot and negatively with batch size. In other words, price formation by private traders is of the retrograde type. Further, traders hold very low stocks and use little credit; the investment-to-trade ratio varies mostly between Rs. 4 and Rs. 20 per maund with a median value of Rs. 7 per maund. They aim at maximization of turnover speed, as illustrated, amongst others, by the rapid succession of purchase and sale transactions. Finally, it can be added that the picture which emerges from this description of wheat traders in the

${ }^{7}$ In a study based on a survey in Kamoke and Chichawatny in 1972, Schmidt still found that the majority of agents worked for sellers as well as for buyers [10].

${ }^{8} \mathrm{~A}$ mandi is a regional market-place where wholesale trade in agricultural produce is concentrated.
Punjab, including the pattern of specialization, applies, broadly speaking, also to traders in Sind. In the NWFP, however, the situation is different. Because the harvested volume of wheat is much smaller there, the trade flows are not large enough to support the degree of specialization achieved in the Punjab and in Sind. The wheat harvest is also too small to satisfy the consumption needs for wheat in that province. As a result, wheat prices are $25-35$ percent higher throughout the wheat-market chain - beginning with the farmers - such that the procurement price is not competitive and procurement of wheat, therefore, is negligible. ${ }^{9}$

\section{A Wheat-trade Table for the Punjab}

In Table 1 , the rows indicate the sale transactions, or, more generally, the distribution of outflows from one actor group among various users, whereas the columns indicate purchase transactions, or the distribution of inflows from various suppliers towards one user group. The first six rows are reserved for shopkeepers, beoparis, "small" commission agents, "large" commission agents, ${ }^{10}$ wholesalers and procurement centres, respectively. The next two rows are for the original suppliers of wheat, viz. farmers and earners of wages in kind. The actors in the first six columns are identical with those in the first six rows. The four columns which then follow comprise the final uses of wheat, where the word "final" should not be taken literally, because government and private milling activities which take in wheat to produce flour for subsequent consumption are also included. Other final uses are wheat consumption and wheat surplus. The latter variable indicates the difference between the volume procured and the volume released by the state in the province of the Punjab. With the ban on interprovincial private wheat-trade still prevailing in 1982, the surplus represents the amount of wheat available for release by the state in deficit provinces.

The objective now is to find approximative values of the flows of trade corresponding to that table. The survey results do not give the size of the flows directly as they are based on a sample, but, if the pattern of trade they delineate is sufficiently robust, they nevertheless provide the framework for a simple algorithm by which the actual flows can be approximated. For example, the survey may tell which percentage of their total sales the beoparis direct to wholesalers (in the Punjab, approximately 2.4 percent) and to other buyers and such proportions may also be obtained for other supplier groups. Thus, a matrix can be constructed consisting of coefficients which describe the trade network from the viewpoint of suppliers.

${ }^{9}$ For a more detailed analysis of the wheat markets in the Punjab, Sind and the NWFP, see Cornelisse [1].

10 "Small" commission agents and "large" commission agents have an annual turnover of less than 25,000 maunds and more than 25,000 maunds, respectively. 
In this matrix, coefficients on the same row add up to one. But the same flows can also be examined from the viewpoint of users. Referring to the same example, the survey may tell which percentage of their total purchases wholesalers obtain from beoparis (approximately 26 percent in the Punjab) and from other suppliers. Repeating this excercise for other user groups, a second matrix can be formed of the same network of trade, but this time with a view to origins of inflow. And in this case the coefficients in each column add up to one. In principle the survey data permit the filling up of the two matrices for each of the provinces of the Punjab, Sind and the NWFP, but, unfortunately, the variances of the coefficients calculated for the latter two provinces exceed the standard for statistical significance. The table can, therefore, be constructed only for the Punjab.

So far, we only have trade coefficients, but no trade flows. Figures for a few flows - needed for the application of the calculation procedure set forth below are available, however. First, there is the volume of the wheat harvest in 1982 of 7,798 thousand tons [7, Table 5] which can be divided among farmers and wages in kind by applying the corresponding parameter derived from the survey data (see Diagram 1). This gives the values of the sums of rows 7 and 8 , viz. 6,956 thousand tons and 842 thousand tons. Then we have the volume of wheat procured by the state, estimated to be 2,479 thousand tons, and the volume of releases by the state to mills of 925 thousand tons [6, p. 102]. The first figure corresponds with the sum value of row and column 6 , and the difference between the two figures indicates the surplus (column 10). Finally, the survey allows estimates of total consumption of ration flour, and private-market flour and wheat corresponding with the sums of columns 7,8 and 9 , respectively. The last three values have been used as initial values in the first round of iterations, and have been adapted slightly in subsequent rounds (see below).

This only leaves for estimation the sums of the first five rows and columns which are, of course, equal for each pair - needed as initial values in the iterative process. Tentative values can be found in two steps. First, the volumes of sales by farmers to each of these groups of private traders can be estimated by multiplying the trade coefficients derived from the survey among farmers by the total of row 7. Then, with the help of the trade coefficients indicating the share of farmers in the purchases of the private trader groups, these volumes can generate the values of total turnover of these groups.

With this complete set of row and column totals, together with the trade coefficients, it is now possible to derive values of individual flows between actor groups. In fact, since there are two matrices of trade coefficients, one relating to origin of inflows and the other to destination of outflows, two sets of individual flows can be calculated. When the two sets of flows are added by row and 
by column, differences may appear to exist with the initial sums of rows and columns. Such differences are obviously a sign of inconsistency, but the newly calculated sums can now be used to generate initial totals for the next iteration, and so on, until convergence is reached. The procedure runs as follows:

I. Adaptation in Rows and Columns 1 to 5 :

(a) If, compared with the initial sum, both newly calculated sums are higher (lower), raise (reduce) the initial sum for the next iteration; and

(b) If the newly calculated sums point in opposite directions, adapt trade coefficients within a margin of 10 percent of the original coefficient value.

\section{Adaptation in Row and Column 6 and in Row 7:}

Change trade coefficients in the desired direction with a maximum of 10 percent as above.

\section{Adaptation in Columns 7, 8 and 9:}

(a) If all three newly calculated column totals are higher (lower), adapt sums in proportion to relative over- (under-) estimation, making sure that the sums add up to $(7798-1554=)$ 6,244 thousand tons and reduce (raise) coefficients to a maximum of 10 percent as above; and

(b) If they point in the different directions, adapt new initial sums, making sure that they add up to 6,244 thousand tons.

This simple iterative procedure appears to converge rapidly to a consistent trade network, as presented in Table 1.

Comments on the figures in the table are limited here to the flows among rader groups, because the remaining parts of the table correspond with other sections of this article: the primary flow of wheat, to which also the last two rows of the table refer, has been discussed in Section 2, whereas the consumption of wheat and flour (included in the final-uses columns) will be taken up in Section 4. The interpretation of figures in the table relating to these items will pose no problem. It must also be stressed here that the figures in Table 1 are of an approximative nature and that there may be small differences between the proportions mentioned in Diagrams 1 and 2 and those in Table 1.

A structural characteristic that can be observed in the table is the triangularity of the strong specialization among traders noted earlier which gives each group a specific position in the wheat-trade chain. Moving down the chain, the proportion of wheat obtained from farmers falls for successive groups of private traders while the part obtained from other dealers rises. This is, in fact, one of the characteristic differences between large and small commission agents. The volume of mutual trade represents a considerable portion of total turnover of wheat by private traders. According to the figures in the table, this proportion reaches a level of approximately 22 percent.

One can also derive the relative importance of the various groups of traders in terms of the total volume handled. While the orders of magnitude are the same for beoparis, small commission agents and large commission agents, it is quite clear that village shopkeepers stand apart with a much smaller volume. They have nevertheless been included in the analysis, because they are a very important group of buyers for small farmers and, thus, form a link between this category of farmers and the wheat market. In terms of the volume traded, wholesalers take an intermediate position.

The table also illustrates the dominating position of the procurement system in the wheat market, as procurement appears to absorb between 70 percent and 75 percent of the marketed surplus of wheat. According to our survey, only slightly less than one-half is obtained from farmers, a proportion which is on the high side if compared with the findings of the Agricultural Prices Commission [5, p. 32] on the basis of a survey among procurement centres in 1981. It found that only the depots with supervisory committees obtain 50 percent of their purchases from farmers, whereas the corresponding figure for other depots is only 34 percent. Still, the purchase pattern of procurement depots according to column 6 of Table 1 is mostly within the range of values of inflow coefficients presented in this other source.

\section{FLOWS OF WHEAT AND FLOUR TO CONSUMERS ${ }^{11}$}

Flow Diagram 2 illustrates the acquisition pattern of wheat and flour of con sumers in rural and urban areas in the Punjab. Even though some of the sources of supply have been aggregated, the pattern appears to be rather intricate - an impres sion which is likely to be strengthened in a subsequent article which will present corresponding information for consumption of wheat in Sind and the NWFP and which will also distinguish between consumers of different income categories.

The diagram illustrates, amongst other things, the considerable difference in the wheat-to-flour ratio of consumption between rural and urban areas. Because of the preponderance of wheat from own-farming and wages in kind, the ratio is, of course, high in rural areas. On the other hand, in order to satisfy demand for wheat or flour in towns and cities, wheat is collected and moved in bulk. This facilitates the milling of wheat in bulk, which is considerably cheaper than the small-scale

\footnotetext{
${ }^{11}$ This section is largely based on Hans de Kruijk [4].
} 
by column, differences may appear to exist with the initial sums of rows and columns. Such differences are obviously a sign of inconsistency, but the newly calculated sums can now be used to generate initial totals for the next iteration, and so on, until convergence is reached. The procedure runs as follows:

\section{Adaptation in Rows and Columns 1 to 5 :}

(a) If, compared with the initial sum, both newly calculated sums are higher (lower), raise (reduce) the initial sum for the next iteration; and

(b) If the newly calculated sums point in opposite directions, adapt trade coefficients within a margin of 10 percent of the original coefficient value.

\section{Adaptation in Row and Column 6 and in Row 7:}

Change trade coefficients in the desired direction with a maximum of 10 percent as above.

III. Adaptation in Columns 7,8 and 9:

(a) If all three newly calculated column totals are higher (lower), adapt sums in proportion to relative over- (under-) estimation, making sure that the sums add up to (7798-1554=) 6,244 thousand tons and reduce (raise) coefficients to a maximum of 10 percent as above; and

(b) If they point in the different directions, adapt new initial sums, making sure that they add up to 6,244 thousand tons.

This simple iterative procedure appears to converge rapidly to a consistent trade network, as presented in Table 1.

Comments on the figures in the table are limited here to the flows among trader groups, because the remaining parts of the table correspond with other sections of this article: the primary flow of wheat, to which also the last two rows of the table refer, has been discussed in Section 2, whereas the consumption of wheat and flour (included in the final-uses columns) will be taken up in Section 4. The interpretation of figures in the table relating to these items will pose no problem. It must also be stressed here that the figures in Table 1 are of an approximative nature and that there may be small differences between the proportions mentioned in Diagrams 1 and 2 and those in Table 1.

A structural characteristic that can be observed in the table is the triangularity of trade among wheat dealers. It reflects, of course, the strong specialization among traders noted earlier which gives each group a specific position in the wheat-trade chain. Moving down the chain, the proportion of wheat obtained from farmers falls for successive groups of private traders while the part obtained from other dealers rises. This is, in fact, one of the characteristic differences between large and small commission agents. The volume of mutual trade represents a considerable portion of total turnover of wheat by private traders. According to the figures in the table, this proportion reaches a level of approximately 22 percent.

One can also derive the relative importance of the various groups of traders in terms of the total volume handled. While the orders of magnitude are the same for beoparis, small commission agents and large commission agents, it is quite clear that village shopkeepers stand apart with a much smaller volume. They have nevertheless been included in the analysis, because they are a very important group of buyers for small farmers and, thus, form a link between this category of farmers and the wheat market. In terms of the volume traded, wholesalers take an intermediate position.

The table also illustrates the dominating position of the procurement system in the wheat market, as procurement appears to absorb between 70 percent and 75 percent of the marketed surplus of wheat. According to our survey, only slightly less than one-half is obtained from farmers, a proportion which is on the high side if compared with the findings of the Agricultural Prices Commission [5, p. 32] on the basis of a survey among procurement centres in 1981. It found that only the depots with supervisory committees obtain 50 percent of their purchases from farmers, whereas the corresponding figure for other depots is only 34 percent. Still, the purchase pattern of procurement depots according to column 6 of Table 1 is mostly within the range of values of inflow coefficients presented in this other source.

\section{FLOWS OF WHEAT AND FLOUR TO CONSUMERS ${ }^{11}$}

Flow Diagram 2 illustrates the acquisition pattern of wheat and flour of consumers in rural and urban areas in the Punjab. Even though some of the sources of supply have been aggregated, the pattern appears to be rather intricate - an impression which is likely to be strengthened in a subsequent article which will present corresponding information for consumption of wheat in Sind and the NWFP and which will also distinguish between consumers of different income categories.

The diagram illustrates, amongst other things, the considerable difference in the wheat-to-flour ratio of consumption between rural and urban areas. Because of the preponderance of wheat from own-farming and wages in kind, the ratio is, of course, high in rural areas. On the other hand, in order to satisfy demand for wheat or flour in towns and cities, wheat is collected and moved in bulk. This facilitates the milling of wheat in bulk, which is considerably cheaper than the small-scale

${ }^{11}$ This section is largely based on Hans de Kruijk [4]. 


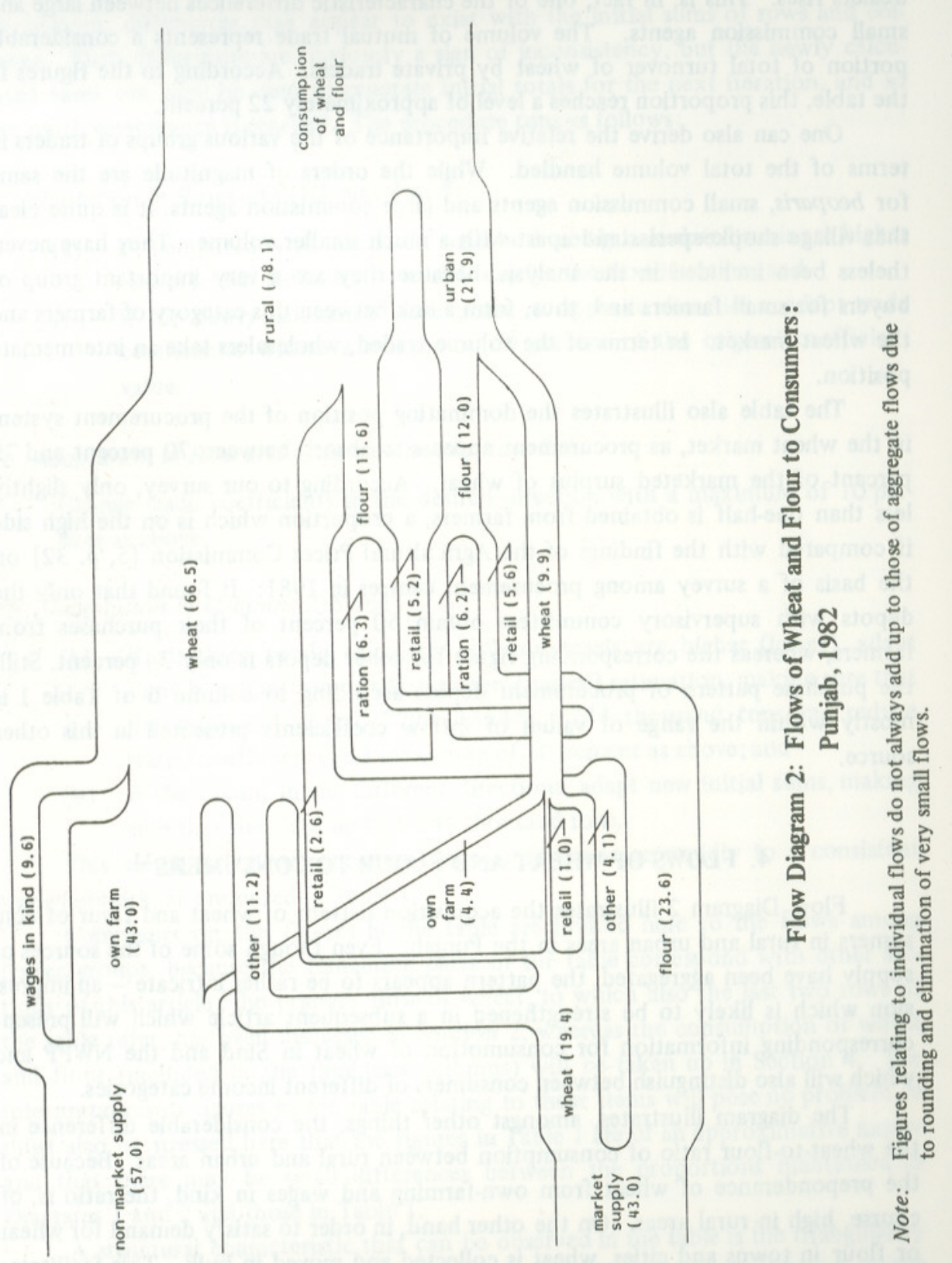

milling by chakkis (village mills), such that the proportion of wheat in urban consumption of wheat and flour is reduced substantially. Because of other differences in the patterns of acquisition of urban and rural areas, the two will be discussed separately below.

Approximately two-thirds of the consumption of wheat and flour in rural Punjab originates in farming and wages in kind. The rest, one-third, consists of wheat and flour obtained through purchases from various sources, mostly, of course, by consumers who are not themselves directly engaged in wheat production. Still, there are also farmers covering the deficit between production and their families' consumption needs by purchases in the market. Some of them even appear to sell wheat first and to buy it again later on. But the number of distress sales among the latter cases is probably rather small. Note further that a significant portion of rural consumption consists of ration flour, although the official aim of the distribution system for the Punjab is to provide ration flour only to consumers in urban centres.

The diagram also shows that a remarkably high percentage of urban consumption of wheat and flour in the Punjab originates in own-farming. In fact, the term "own-farming" is not to be taken literally and really stands for obtainment of wheat free of charge from family farms operated by relatives, or from land tilled by tenants. This flow involves, on average, about 20 percent of urban consumption, but in the next article it will be shown that high-income groups derive a much larger share of wheat and flour consumption from own-farming than the low-income groups. Therefore, the urban poor depend considerably more on the proper operation of the wheat market than do consumers with higher incomes. As can be expected, the pattern of consumption of ration flour displays an inverse tendency. While ration flour represents, on average, nearly 30 percent of urban consumption, the percentage is higher for low-income groups than for groups at the other end of the income scale.

\section{CONCLUSIONS}

In this article, a description has been given of the network of wheat flows between farmers, traders and consumers in the Punjab. The figures collected for this purpose have been summarized in two diagrams and in a trade table to which the reader is referred for a survey of the magnitude and composition of the movements of wheat. This section lists some conclusions regarding the activities of wheat traders which can be derived from the description in the foregoing pages as an introduction to a more detailed evaluation in a subsequent article.

Private wheat-traders in the Punjab display a fairly high degree of specializa tion which expresses itself in differences in the size of the area they cover and in the 
magnitude of individual transactions. For this reason, farmers with different supplies of marketable wheat tend to sell to different categories of middlemen. Therefore, also, the position of groups of traders in the wheat-trade chain varies: some groups buy exclusively or nearly exclusively from farmers, while others buy a considerable share from other traders.

Credit is scarce among wheat traders; as a rule, they provide only little of it to their customers. For the same reason, relatively little wheat is stored and, thus, also storage for speculative purposes is probably rare. In general, buying and selling transactions follow each other in rapid succession, as traders attempt to maximize the turnover speed. This working method and a relatively keen competition lead to mark-up charges of moderate size.

It follows that the functions carried out by wheat traders in the Punjab are rather limited, consisting mainly of collection, transportation and enlargement of batch sizes. The contribution by private traders to the function of price formation is also of limited importance, as transaction prices are determined mainly by deducting a margin that varies negatively with batch size and positively with distance to the nearest depot, from the procurement price. This wheat procurement price dominates the wheat market, as procurement by the state absorbs more than 70 percent of the marketed surplus in the Punjab. The advantage to farmers is, of course, that price formation is much clearer and that, in terms of market information, they are not as much at a disadvantage $v i s-a-v i s$ middlemen as they may otherwise be.

\section{REFERENCES}

1. Cornelisse, P. A. Wheat Trade and Wheat Traders in Pakistan. Rotterdam: Erasmus University/Islamabad : Pakistan Institute of Development Economics. 1983. (Working Paper No. 7 of a joint E.U.R.-P.I.D.E. project)

2. Cornelisse, Peter A., and Syed Nawab Haider Naqvi. The Anatomy of the Wheat Market in Pakistan. Rotterdam: Erasmus University/Islamabad: Pakistan Institute of Development Economics. Forthcoming, 1984.

3. van Gaalen, Th. M. P. The Primary Wheat Market - Evidence from Pakistan. Rotterdam: Erasmus University/Islamabad: Pakistan Institute of Development Economics. 1983. (Working Paper No. 6 of a joint E.U R.-P.I.D.E. project)

4. de Kruijk, Hans. The Consumption of Wheat (Flour) in Pakistan. Rotterdam : Erasmus University/Islamabad: Pakistan Institute of Development Economics. 1983. (Working Paper No. 8 of a joint E.U.R.-P.I.D.E project)

5. Pakistan. Agricultural Prices Commission. Punjab Wheat Disposal Survey. Islamabad. 1983. (APCOM Series No. 1)
6. Pakistan. Finance Division. Economic Adviser's Wing. Pakistan Economic Survey, 1982-83. Islamabad. 1983.

7. Pakistan. Ministry of Food, Agriculture and Co-operatives. Food and Agriculture Division. Agricultural Statistics of Pakistan, 1982. Islamabad. 1983.

8. Pakistan. Statistics Division. Federal Bureau of Statistics. Household Income and Expenditure Survey, 1979. Karachi. 1983.

9. Roks, J. M. M. "The Marketed Surplus of Wheat in the Punjab". Unpublished Master's thesis (in Dutch), Erasmus University, Rotterdam. 1984.

10. Schmidt, G. Vermarktungsstyme für Landwirtschaftliche Produkte in Pakistan Saarbrïcken: Verlag Breitenbach. 1976. 